North, A. C. and Hargreaves, D. J. (1998). Affective and evaluative responses to music. Current Psychology, 17, 102-108.

\title{
Affective And Evaluative Responses To Pop Music
}

\author{
Adrian C. North and David J. Hargreaves
}

Music Research Group, Department of Psychology, University of Leicester, University Road,

Leicester LE1 7RH

U.K. 


\begin{abstract}
From reviews published in the 'serious' pop music press, 20 recordings were selected which had received consistently favourable appraisals on affective and evaluative bases. A further 20 recordings were selected on the basis of high levels of chart performance but a lack of critical acclaim. Sixty-four subjects rated representative excerpts of these recordings on 11-point scales of either liking or artistic merit. The results indicated significantly lower liking and artistic merit ratings of criticallypraised excerpts; a positive liking-artistic merit correlation; and some 'fragmentation' between affective and evaluative responses. The apparent discrepancy between the attitudes of the music press and subjects' ratings is discussed in terms of the availability and sophistication of evaluation cues.
\end{abstract}




\section{Affective And Evaluative Responses To Pop Music}

Despite the prevalence of music criticism in the media, few studies have addressed the degree to which individuals' responses to pop music correspond with overt statements made by pop music critics. Empirical and anecdotal evidence indicates that the degree of correspondence between these two types of response may be very small.

Furthermore, although two studies (Hargreaves, Messerschmidt, and Rubert, 1980; Hargreaves, 1988) have found positive correlations between ratings of 'liking' and 'quality' assigned to music, further research is needed to determine the fundamental general features of this relationship. This present research addresses these two issues.

Although Farnsworth (1969) found agreement between expert and public groups on 'eminence' (i.e. artistic worth) rankings of classical music composers, pop music generally contains fewer technical cues of compositional worth. Subsequent aesthetic responses should incorporate a greater subjective component, increasing the probability that subjects' ratings will fail to reflect the opinions of pop music critics. Indeed, Konecni (1984) found that subjects' ratings failed to reflect manipulations of artworks that reduced their artistic worth, but left technical qualities intact (e.g. the rotation of paintings through 90 and 180 degrees). Clearly, the public often fails to identify those aspects of artworks which critics would regard as fundamental to their artistic merit.

The 'serious' British pop music press frequently makes explicit statements concerning the artistic status of specific pop music recordings. The coverage of pop music by other 'serious' arts media closely corresponds with these statements, indicating their credibility in the artworld. 'Serious' pop music newspapers (e.g. Melody Maker; The New Musical Express) strongly contend that some pop music artists consistently produce high quality art (hereafter, 'art pop'). These recordings are readily identifiable through consistently favourable reviews which emphasise the thoughtful approach of 
the artists to their music, and the status of that music as an artwork (see e.g. 'Melody Maker', 14 May 1994 p. 12). By contrast, 'chart pop' recordings are readily identifiable through, often overtly critical, reviews discussing their low 'artistic worth', and commercial emphasis (see e.g. 'Melody Maker', 14 May 1994 p. 30). This distinction between 'art pop' and 'chart pop' is essentially identical to that made by Vulliamy (1977) in contrasting 'rock' and 'pop'. Note however, that despite the overtly stated worthiness of 'art pop', 'Top-20' record charts confirm that it enjoys little commercial success.

In addressing this issue, subjects in the present study rated forty unidentified excerpts of 'art pop' and 'chart pop' for either 'liking' or 'artistic merit'. The relatively poor commercial success of 'art pop', and research indicating a positive correlation between ratings of 'liking' and 'quality', suggests that subjects should assign higher 'liking' and 'artistic merit' ratings to excerpts of 'chart pop'. However, an alternative possibility is that 'liking' and 'artistic merit' ratings will separate or 'fragment', representing the detachment of affective from evaluative responses: 'art pop' excerpts may receive higher 'artistic merit' ratings, whilst 'chart pop' excerpts may receive higher 'liking' ratings (see Rosenberg and Abelson, 1960). Subjects' overt statements of the criteria defining 'artistic merit' were also collected.

\section{Method}

Subjects 64 subjects (13 males, 51 females) from a central Leicester sixth-form college volunteered to participate in the study, and were randomly assigned to a 'Liking' or an 'Artistic Merit' group. Mean age was 17.9 years (s.d. $=1.21$, range $=16$ - 22 years) representing the target audience of the 'serious' pop music press. Informal pre-experimental discussions with teachers confirmed that pupils at the college were from similar socioeconomic backgrounds. On the basis of 4 independent judges' assessments of responses to a self-report measure of musical training and experience, 
15 subjects were assigned to a 'high training' group, 21 to an 'intermediate training' group, and 28 to a 'low training' group. These assignations were based primarily on subjects' level of formal musical tuition. Approximately half the number from 'high', 'intermediate', and 'low' training groups appeared in each group, i.e. 8, 7, and 17 respectively in the 'liking' group; and 7, 11, and 14 respectively in the 'artistic merit' group.

Experimental Stimuli Ten 'art pop' albums and ten 'chart pop' albums were quasirandomly selected on the basis of a review of virtually all editions of the British pop music newspaper 'Melody Maker' dated between 1989-1994. 'Art pop' albums were selected on the basis of consistently favourable reviews emphasising their importance as artworks, the profound causes of their appeal, and the artistic (as opposed to commercial) intentions of the artist. 'Chart pop' albums were selected from the national 'Top 20' chart and had been frequently criticised in either review or discussion articles on affective and evaluative grounds. In both classifications, the consistency of comments was a crucial factor in selection. In practice, the emphasis of the music press on artistic worthiness made the identification of appropriate recordings a simple task.

Two tracks were quasi-randomly selected from each album, and a random ordering of thirty second representative excerpts was recorded onto audio tape. A ten second gap was inserted between excerpts to allow subjects to mark their rating. Names of artists, song titles, and the class of music from which they were drawn, were withheld throughout the experiment. Details of the excerpts appear in Appendix 1.

Design And Procedure In an independent subjects design, equal numbers of subjects rated all 40 excerpts for either 'liking' or 'artistic merit'. The two groups were tested simultaneously in separate rooms with subjects seated in a series of outward-facing semi-circles, preventing non-verbal communication. Subjects read instructions from 
their Response Sheet which were verbally reinforced. The 40 excerpts were then played. Immediately after presentation, subjects were asked to rate each excerpt on an 11-point scale of liking or artistic merit. Subjects then completed Section B of the Response Sheet, including for 'artistic merit group' subjects, an open-ended item requesting the statement of factors which constitute high artistic merit.

\section{Results}

Figure 1 shows the scatter diagram of the relationship between mean liking and mean artistic merit ratings over all 40 excerpts. The product-moment correlation coefficient over these ratings is $+0.96(\mathrm{~N}=40, \mathrm{p}<0.001)$ indicating a very strong positive, linear relationship.

- Figure 1 about here -

t-tests support the visual impression from Figure 1 that these ratings fall into two groups. 'Chart pop' excerpts received significantly higher liking ratings than 'art pop' excerpts $(x=5.58$ and 2.17 respectively, $t=10.57$, d.f. $=38, p<0.001)$. Similarly, 'chart pop' excerpts received significantly higher artistic merit ratings than 'art pop' excerpts $(\mathrm{x}=4.81$ and 2.49 respectively, $\mathrm{t}=8.57$, d.f. $=38, \mathrm{p}<0.001)$.

Ratings were further investigated by means of a 3 (level of training) x 2 (type of music i.e. 'art pop' or 'chart pop') x 2 (rating dimension i.e. 'liking' or 'artistic merit') ANOVA, with level of training and rating dimension as between subjects variables. Results of this are reported in Table 1.

-Table 1 about here - 
'Level of training', 'type of music', and 'rating dimension' were significant main effects, and all the possible 2-way interactions between these also reached significance. The 3-way interaction was non-significant. However, the type of music and level of training main effects are uninterpretable since both analyses collapse 'liking' and 'artisitic merit' ratings into one dimension. Similarly the two-way interaction between type of music and level of training is uninformative, given the non-significant 3-way interaction where the two rating dimensions are separated out. Therefore, only the rating dimension $\mathrm{x}$ type of music, and rating dimension $\mathrm{x}$ level of training 2-way interactions were considered further.

- Figure 2 about here -

Figure 2 plots the rating dimension x type of music interaction. Although 'chart pop' excerpts received higher 'liking' than 'artistic merit' ratings, this pattern was reversed in ratings of 'art pop' excerpts, indicating the separation or 'fragmentation' of these measures. Therefore, the rating dimension main effect, showing that 'liking' ratings were on average higher than 'artisitic merit' ratings ( $\mathrm{x}=3.91$ and 3.55 respectively), can be seen as misleading.

- Figure 3 about here -

Figure 3 shows the rating dimension $\mathrm{x}$ level of training interaction, the most salient aspect being that the high training group assigned the highest liking ratings but the lowest artistic merit ratings. In concordance, Table 2 displays relatively low productmoment correlation coefficients between liking and artistic merit ratings assigned by highly trained subjects to 'art pop' and 'chart pop' excerpts separately. $\mathrm{z}^{1}$ transformation tests (see Edwards, 1960) were conducted to test whether the differences between these coefficients were significant. The correlation between 'liking' and 'artistic merit' ratings assigned by the 'intermediate training' group to 'art 
pop' excerpts was significantly higher than the correlation between ratings of these measures assigned by the 'high training' group to 'chart pop' excerpts $(\mathrm{z}=2.55, \mathrm{p}<$ 0.05). Obtained $\mathrm{z}$ values from all other possible combinations were non-significant, ranging between 1.86 and 0.29 .

- Table 2 about here -

\section{Discussion}

The results clearly indicate that subjects' liking and artistic merit ratings were discordant with overt statements published by the serious pop music press regarding relative responses to 'art pop' and 'chart pop'. Measures of liking and artistic merit were significantly higher for 'chart pop' excerpts. These significant differences concur with Konecni (1984) in indicating that subjects failed to respond to stimulus features that the music press regard as indicative of musical worth. However, the discrepancy between these results and Farnsworth's conclusion concerning agreement between expert and public groups is not as great as may initially appear. The high likingartistic merit correlation $(\mathrm{r}=+0.96$, see Figure 1) indicates that subjects' responses were indeed lawful: rather, the laws upon which subjects' ratings were based lead them to assign low ratings to excerpts advocated by the music press.

Figure 2, and the rating dimension $\mathrm{x}$ type of music interaction, indicate the fragmentation between affective and evaluative responses: 'art pop' excerpts received higher artistic merit than liking ratings whereas ratings of 'chart pop' excerpts were in the opposite direction. Subjects were, therefore, capable of accepting to a degree that 'chart pop' was liked but not 'high quality' music, whereas 'art pop' was disliked but still recognised as supposedly 'high quality' music. However, this fragmentation only occurred within each type of music: 'chart pop' excerpts received higher ratings on both dimensions. Figure 3 and Table 2 indicate that 'high training' subjects were more 
likely to fragment affective and evaluative responses, which is at variance with the findings of Hargreaves et al (1980) who found fragmentation to be most likely amongst subjects with little or no musical training.

The principal importance of this fragmentation evidence is in indicating that subjects were aware of the supposed higher quality of 'art pop' excerpts. However, the generally higher ratings assigned to 'chart pop' suggests that subjects' attitudes concerning the relative merits of 'art pop' and 'chart pop' were simply based on different criteria to those employed by the music press. The cause of this, and the apparent discrepancy between the present study and Farnsworth's conclusion concerning agreement between expert and public groups, seems attributable to differences in the sophistication of affective and evaluative appraisal cues.

Farnsworth's conclusions were based on classical music: this idiom contains many objective, technical cues of musical worth such as the use of thematic motifs, harmonic development etc.. These may be readily appreciated by lay listeners and experts alike, on both evaluative and affective grounds, culminating in expert-public agreement. In contrast, pop music rarely contains these technical, readily appreciable cues. Subsequent affective and evaluative responses will, by necessity, reflect a greater subjective component, thereby increasing the potential for discrepancies between subjects' appraisals and those overtly expressed by the pop music press.

An exploratory content analysis of artistic merit group subjects' rating criteria provides considerable support for this assertion. Simple, objective elements were most frequently reported, with 'instrumentation' and 'rhythm/beat' declared by the 32 subjects' on 15 and 14 occasions respectively. In contrast, descriptions of 'high quality' music in a recent edition of 'Melody Maker' (23 April 1994, p.27) employ relatively sophisticated and subjective criteria such as 'fragile thunder' ('Dreams' The Cranberries), 'lush dynamism' ('Starethrough EP' Seefeel), and 'fabulous angles' ('15 Ways' The Fall). 
In conjunction with the above evidence indicating fragmentation, this supports the earlier conclusion that subjects' responses are lawful, but that these laws differ from those employed by the music press. The present evidence implies that the expert's 'lush dynamism' may well be the lay-listener's 'rhythmless noise'. Moreover, the high correlation obtained between 'liking' and 'artistic merit' ratings, combined with the apparent discrepancy between subjects' ratings and the overt statements of the music press indicates that, within peer groups, affective and evaluative appraisals of pop music may be essentially equivalent.

\section{Acknowledgement}

The authors are greatly indebted to Ed O'Grady of Wyggeston Collegiate, Leicester for providing access to subjects and assisting in testing. 


\section{References}

Edwards, A. L. (1960) Experimental Design In Psychological Research New York: Holt, Rinehart And Winston.

Farnsworth, P.R. (1969) The Social Psychology Of Music (2nd edition). Ames: Iowa State University Press.

Hargreaves, D. J. (1988) Verbal and behavioral responses to familiar and unfamiliar music. Current Psychological Research And Reviews, $\underline{6}$, 323-330.

Hargreaves D.J., Messerschmidt, P., and Rubert, C. (1980) Musical preference and evaluation. Psychology Of Music, $\underline{8}, 13-18$.

Konecni, V. J. (1984) Elusive effects of artists' hidden 'messages'. in Crozier, W. R. and Chapman, A. J. (Eds.) Cognitive Processes In The Perception Of Art. NorthHolland: Elsevier Science Publishers B.V.

Melody Maker. London: IPC Magazines.

Melody Maker 23 April 1994. London: IPC Magazines.

Melody Maker 14 May 1994. London: IPC Magazines.

Rosenberg, M. J. and Abelson, R. P. (1960) An analysis of cognitive balancing. in Rosenberg, M. J., Hovland, C. I., McGuire, W. J., Abelson, R. P., and Brehm, J. W. (Eds.) Attitude Organisation And Change: An Analysis Of Consistency Among Attitude Components. Yale University Press: New Haven. 
The New Musical Express. London: IPC Magazines.

Vulliamy, G. (1977) Music and the mass culture debate, in J. Shepherd, P., Virden, G.

Vulliamy, and T. Wishart (eds.) Whose Music ? A Sociology Of Musical Languages.

London: Latimer. 


\section{Appendix 1 - Experimental Music}

Art Pop Excerpts.

'Catatonic' and 'Mad pilot' - Babes In Toyland; 'Hair' and 'O Stella' - P.J. Harvey;

'Purr' and 'J.C.' - Sonic Youth; 'To love is to bury' and 'Walking after midnight' -

Cowboy Junkies; 'Angel' and 'Dusted' - Belly; 'I'm no iron man' and 'Lonesome

bulldog pt. 1' - The Butthole Surfers; 'Black sheets of rain' and 'It's too late' - Bob

Mould; 'Eye of the storm' and 'You, the night, and the music' - Gallon Drunk; 'Leaves

of summer' and 'Starblood' - Cranes; 'Master of puppets' and 'The things that should not be' - Metallica.

Chart Pop Excerpts.

'Hurt no more' and 'Unconditional' - Charles And Eddie; 'Comin' on' and 'Fatman' -

The Shamen; 'Waiting for a girl like you' and 'How long' - Undercover; 'Voulez-vous danser' and 'Munchhausen' - Ace Of Base; 'Ooops up' and 'Believe the hype' - Snap; 'Outstanding' and 'Were we ever in love' - Kenny Thomas; 'The power age' and 'Mysterious' - 2 Unlimited; 'Cherish the day' and 'No ordinary love' - Sade; 'Lonely Heart' and 'Please don't go' - Boyz II Men; 'So long movin' on' and 'Picture my world' - D:Ream. 


\begin{tabular}{lccc}
\hline \hline Source Of Variance & d.f. & F & p \\
\hline Rating Dimension & 1 & 7.44 & 0.007 \\
Type Of Music & 1 & 451.69 & $<0.001$ \\
Level Of Training & 2 & 3.96 & 0.02 \\
Rating Dimension x Type Of Music & 1 & 23.34 & $<0.001$ \\
Rating Dimension x Level Of Training & 2 & 7.85 & 0.001 \\
Type Of Music x Level Of Training & 2 & 3.55 & 0.03 \\
Rating Dimension x Type Of Music x Level Of Training & 2 & 0.73 & 0.48 \\
\hline
\end{tabular}

Table 1 - Summary Table Of The Effects Of Rating Dimension, Type Of Music And Musical Training 


\begin{tabular}{|c|c|c|c|}
\hline & Low Training & Intermediate Training & High Training \\
\hline Chart Music & $+0.75^{* *}$ & $+0.79^{* *}$ & $+0.50^{*}$ \\
\hline Art Music & $+0.83^{* *}$ & $+0.89^{* *}$ & $+0.67^{* *}$ \\
\hline
\end{tabular}

Table 2 - Product-Moment Correlations Between Liking And Artistic Merit Ratings In Each Training x Type Of Music Category 